Research, part of a Special Feature on Sustainability Impact Assessment of Forest Management Alternatives in Europe

\title{
Public Preferences Across Europe for Different Forest Stand Types as Sites for Recreation
}

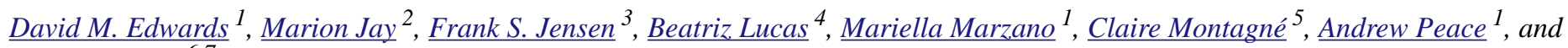 \\ Gerhard Weiss 6,7
}

\begin{abstract}
A Delphi survey involving experts in forest preference research was carried out to derive scores for the recreational value of 240 forest stand types across Europe. The survey was organized around four regional panels: Great Britain, Nordic Region, Central Europe, and Iberia. In each region, 60 forest stand types were defined according to five forest management alternatives (FMAs) on a continuum of management intensity, four phases of development (establishment, young, medium, and adult), and three tree species types (conifer, broadleaved, and mixed stands of conifer and broadleaved). The resulting scores were examined using conjoint analysis to determine the relative importance of the three structural attributes (FMA, phase of development, and tree species type), and each level or component of the attributes. The findings quantify the extent to which forest visitors prefer a degree of management to unmanaged forest nature reserves across the four regions. Phase of development was shown to make the highest contribution to the recreational value of forests while the contribution of tree species type was shown to be relatively unimportant. While the results are indicative, they provide evidence to support long-term retention and low-impact silviculture in forests where recreation is a primary objective of management.
\end{abstract}

Key Words: Delphi; Europe; forest management; public preference; recreation; structural attribute

\section{INTRODUCTION}

The field of forest preference research has contributed much to our understanding of the impacts of management interventions on the aesthetic and recreational values of forests (e.g. Zube et al. 1982, Brown and Daniel 1984, Jensen and Koch 1998, Lee 2001, Silvennoinen et al. 2001, Blasco et al. 2009). Within this literature, perhaps the most fundamental question has been the extent to which the visiting public prefers managed or unmanaged forests (Ribe 1989, Tyrväinen et al. 2005). While this issue has been frequently addressed, the majority of work has focused on specific case study areas, and relatively few comparative studies or meta-analyses have been conducted (Ribe 1989, Gundersen and Frivold 2008, Schraml and Volz 2009, Zandersen and Tol 2009, Arnberger et al. 2010, Edwards et al., in press). We address this gap by quantifying the recreational value of forests using a Delphi survey involving experts in forest preference research in four contrasting regions of Europe: Great Britain, the Nordic Region, Central Europe, and Iberia. Recreational value was defined in terms of the preferences of people who regularly use forests as sites for recreation. Preferences for a given forest are likely to be influenced by many factors, both on-site, such as recreational infrastructure and services, and off-site, such as proximity to centers of population and alternative forest and non-forest recreational opportunities (Hill et al. 2003, Edwards et al. 2011). To keep the goals of the study within manageable limits, we focused only on three structural attributes of the forest, namely, management intensity, tree age, and tree species, at the forest stand or forest management unit level.

One of the difficulties with comparative studies of preferences for forests is the need to standardize the variation in management regimes. To resolve this problem, we used the typology of forest management alternatives (FMAs) developed by Duncker et al. (in press) which simplifies the silvicultural diversity of Europe's forests into five types located along a continuum of management intensity. This typology was further differentiated into four phases of development and three tree species types to produce a total of 60 forest stand types for each region. We obtained scores on a ten-point scale for the recreational value of each forest stand type through a Delphi survey undertaken simultaneously in the four regions (Edwards et al. 2010a). The resulting scores were later extrapolated to cover every country in Europe and used as input data for European scenario analysis (Edwards et al. 2011, UNECE/FAO 2011, M.-J. Schelhaas, M. Didion, E. Arets, D. Edwards, G. Hengeveld, M. Lindner, B. Mason, A. Moiseyev, G.-J. Nabuurs unpublished manuscript).

This study, however, focuses on analysis of the recreational scores, and how these are composed of the three attributes used to define the 60 forest stand types. The main objectives are to determine the relative importance of: (1) the three structural attributes, and (2) each level or component of the three attributes, i.e., the five FMAs, four phases of

\footnotetext{
${ }^{1}$ Forest Research, ${ }^{2}$ Institute of Forest and Environmental Policy, Albert-Ludwigs University, ${ }^{3}$ Forest \& Landscape, Faculty of Life Sciences, University of Copenhagen, ${ }^{4}$ Centre Tecnologic Forestal de Catalunya (CTFC), ${ }^{5}$ Laboratoire d'économie forestière, UMR INRA AgroParisTech-ENGREF, ${ }^{6} \mathrm{Central} \mathrm{East-}$ European Regional Office of the European Forest Institute (EFICEEC), ${ }^{7}$ University of Natural Resources and Life Sciences (BOKU)
} 
development, and three tree species types. In each case we also examine variation between regions. The discussion interprets the findings by drawing from previous published research, including a companion study conducted by the authors as part of the same Delphi survey, which assessed the relationship and relative contribution of a broader range of attributes ( 12 in total) to the recreational value of forests in the same four regions (Edwards et al. 2010b, Edwards et al., in press). In contrast, the study reported here assessed the forests themselves, and then decomposed the results using conjoint analysis to assess the contribution of the three key attributes that we had used to define them. In doing so, we quantify public preferences for management intensity and the extent to which generalizations are possible across Europe. The wide applicability of our findings should attract the interest of managers and policy makers who seek accessible evidence to support recreational planning within the context of multifunctional land use.

\section{METHODS}

A typology of 60 forest stand types was defined within a matrix comprising five forest management alternatives (FMAs), four phases of development, and three tree species types. The FMAs were located on a continuum of management intensity as follows: (1) forest nature reserves; (2) close-to-nature forestry; (3) combined objective forestry; (4) intensive, even-aged forestry, and (5) woody biomass production (Duncker et al. in press). The phases of development were: (1) establishment (0-5 years, less than 2 meters in height), (2) young (5-15 years, greater than 2 meters, and up to $7 \mathrm{~cm}$ breast height diameter), (3) medium (15-50 years, up to when most height growth has been reached), and (4) adult (50+ years, after the time when most height growth has been reached). The tree species types were conifer, broadleaved, and mixed stands of coniferous and broadleaved trees.

The 60 forest stand types were assessed as part of a Delphi survey in each of four European regions: (1) Great Britain, i.e., upland areas of Scotland, England, and Wales, (2) the Nordic Region, i.e., boreal areas of Norway, Sweden, and Finland, (3) Central Europe, i.e., southern Germany, Austria, and Switzerland, and (4) Iberia, i.e., Mediterranean areas of Spain and Portugal. These regions were selected to reflect the diversity of biogeographical and socio-cultural contexts in Europe (cf. Pröbstl et al. 2009). In each region, the most common tree genus, by area, was selected to represent each tree species type. In some cases the tree species was given instead of genera when this was judged to be more helpful to survey participants. The genera or species selected in each region were Great Britain: Sitka spruce (Picea sitchensis) and birch (Betula spp.); Nordic Region: Scots pine (Pinus sylvestris) and birch (Betula spp.); Central Europe: Norway spruce (Picea abies) and beech (Fagus sylvatica); and Iberia: pine (Pinus spp.) and oak (Quercus spp.).

\section{The Delphi survey}

Following the protocol of Novakowski and Wellar (2008) we developed a Delphi methodology whereby experts in forest preference research were invited to participate anonymously in a questionnaire survey conducted over successive rounds, organized into four panels with one panel representing each of the four regions (Linstone and Turoff 1975, cf. Landeta 2006, Edwards et al. 2011). The survey was carried out between September 2009 and January 2010 following completion of a pilot phase. Overall, 46 experts participated: 10 in each of the Great Britain and Iberia panels, 12 in the Nordic panel, and 14 in the Central Europe panel (see Acknowledgements). Two rounds were required before stability in the responses was reached (Edwards et al. 2010a).

Potential participants were identified and recruited primarily through the authors' existing professional networks. Candidates who declined the offer to participate were asked to suggest other potential participants. Efforts were made to ensure that the panels were similar in composition, in particular in terms of the academic disciplines and professional roles that were represented, although some bias may have resulted from differences in the academic traditions of forest preference research in each region. One of the reasons for using experts rather than direct sampling of forest visitors was that the questionnaire used a conceptual framework of forest stand types, rather than photographs or computer images, which greatly simplified the task of ensuring that comparable information was presented to each panel. Participants were selected partly on their expected ability to visualize each stand type in their respective regions. An additional criterion for selecting experts was their expected ability to respond on behalf of the public rather than provide their personal viewpoints. Experts in forest preference research, with their links to natural resource management and the human sciences, were seen to be well placed to meet these two criteria.

The questionnaire included a scoresheet comprising a matrix of 60 cells organized according to the three key variables that defined the forest stand types (see Table 1). Participants were asked to fill in each cell with a score on a ten-point scale to indicate how they believed potential visitors would value a forest stand of that type as a location for recreational use. For most visitors, visual attractiveness has a major impact on the recreational value of a forest stand (Brown and Daniel 1984). However, it was highlighted in the questionnaire that some visitors may also value the same stand type for nonvisual reasons, e.g., because they provide better habitats for hunting, bird-watching, or collection of mushrooms and berries. Participants were asked to take these differences into account, and complete the scoresheet on behalf of the "average" visitor. 
Table 1. Median recreational scores for forest stand types, by region.

\begin{tabular}{|c|c|c|c|c|c|c|c|c|c|c|c|c|c|c|c|c|}
\hline \multirow{3}{*}{ Region } & \multirow{3}{*}{$\begin{array}{l}\text { Phase of } \\
\text { Development }\end{array}$} & \multicolumn{15}{|c|}{$\mathrm{FMA}^{\dagger}$} \\
\hline & & \multicolumn{5}{|c|}{ Conifer } & \multicolumn{5}{|c|}{ Broadleaved } & \multicolumn{5}{|c|}{ Mixed } \\
\hline & & 1 & 2 & 3 & 4 & 5 & 1 & 2 & 3 & 4 & 5 & 1 & 2 & 3 & 4 & 5 \\
\hline \multirow{4}{*}{$\begin{array}{l}\text { Great } \\
\text { Britain }\end{array}$} & Establishment & 3 & 3 & 3 & 1 & 1 & 4 & 3.5 & 3.5 & 2.5 & 2 & 4 & 4 & 3.5 & 2.5 & 2 \\
\hline & Young & 3.5 & 3 & 3 & 2 & 1.5 & 6 & 6 & 5 & 3.5 & 2.5 & 5 & 5 & 5 & 4 & 2.5 \\
\hline & Medium & 5 & 5 & 6 & 3 & 2.5 & 8.5 & 8 & 7.5 & 5 & 3.5 & 8 & 8 & 6.5 & 5 & 3.5 \\
\hline & Adult & 6.5 & 7 & 6.5 & 4.5 & - & 10 & 10 & 8 & 6 & - & 8 & 9 & 8.5 & 6 & - \\
\hline \multirow{4}{*}{$\begin{array}{l}\text { Nordic } \\
\text { Region }\end{array}$} & Establishment & 2 & 2 & 2.5 & 1 & 1 & 2 & 2 & 2.5 & 1.5 & 1 & 2 & 2 & 2.5 & 2 & 1 \\
\hline & Young & 2.5 & 3 & 3.5 & 2.5 & 2 & 3 & 3.5 & 4 & 3 & 2 & 3 & 3.5 & 4 & 3 & 2 \\
\hline & Medium & 5.5 & 7 & 7 & 5.5 & 3 & 6 & 8 & 7 & 7 & 4 & 5.5 & 7.5 & 7 & 6 & 4.5 \\
\hline & Adult & 8 & 9 & 9 & 8 & - & 8 & 10 & 9 & 8 & - & 8 & 9 & 10 & 9 & - \\
\hline \multirow{4}{*}{$\begin{array}{l}\text { Central } \\
\text { Europe }\end{array}$} & Establishment & 4 & 4 & 3 & 1 & 1 & 4 & 4 & 3.5 & 2 & 1 & 5 & 4 & 4 & 2 & 2 \\
\hline & Young & 4.5 & 4 & 3 & 2 & 1 & 5.5 & 5 & 4 & 3 & 2 & 5.5 & 5.5 & 4.5 & 3 & 2 \\
\hline & Medium & 6 & 6 & 5 & 3 & 2 & 7 & 7 & 6 & 5 & 3 & 7 & 8 & 7 & 5 & 3 \\
\hline & Adult & 8 & 7.5 & 7 & 4 & - & 8.5 & 9 & 8 & 6 & - & 10 & 9 & 8 & 6 & - \\
\hline \multirow[t]{4}{*}{ Iberia } & Establishment & 2 & 2 & 2 & 1 & 1 & 3 & 3 & 3 & 2 & 1.5 & 3.5 & 3 & 3 & 2 & 2 \\
\hline & Young & 3.5 & 3.5 & 3.5 & 1.5 & 1 & 4 & 5 & 4.5 & 3 & 1.5 & 5 & 6 & 5 & 3.5 & 2 \\
\hline & Medium & 7 & 6.5 & 6 & 4 & 2 & 7 & 7 & 7.5 & 5 & 3 & 8.5 & 9 & 7.5 & 6 & 3 \\
\hline & Adult & 6.5 & 8 & 8 & 5 & - & 8 & 8.5 & 8 & 6 & - & 9.5 & 10 & 9 & 6.5 & - \\
\hline
\end{tabular}

${ }^{\dagger}$ Forest management alternatives (FMAs): (1) forest nature reserves; (2) close-to-nature forests; (3) combined objective forestry; (4) intensive even-aged forestry; (5) wood biomass production.

They were also asked to provide comments or explanatory notes on the decisions that they made.

Participants were requested to use the full range of scores from 1 to 10 across the whole scoresheet. However it was stressed that the matrices for each tree species type could have a different range of scores, e.g., 1-10 for conifers, 2-8 for broadleaved, and 4-10 for mixed stands. They were asked to use full numbers (i. e., no decimals or fractions), and to use the same score for different forest stand types if they felt they were of equal recreational value. They should assume that there was suitable physical access into, alongside, or in close proximity to the stand from which a visitor could judge its recreational value. Scores were to be based on biophysical features only, ignoring paths and other recreational infrastructure that may be present in such a forest type. Participants were also asked to provide a score for every cell, even though in practice some may be very rare, and to provide average scores across all seasons of the year, for example, to allow for differences in appearance of deciduous trees or due to snowfall. However, in response to feedback during Round 1, it was decided to remove adult phase wood biomass production (FMA5) from the questionnaire for Round 2. They were asked to bear in mind that neighboring stands may also be visible, especially when scoring establishment phase stands, and to assume that these were of the same FMA. An appendix was provided giving pan-European definitions of each FMA (see Duncker et al. in press).

At the end of Round 1 the scores and comments were collated and provisional analysis was carried out. Questionnaires for Round 2 were prepared and circulated. These were tailored for each individual: a table was provided, which gave the results from the first round of everyone in their panel, including all of the comments. Also, on a separate page, alongside a new scoresheet, their personal scores from Round 1 were provided. Participants were invited to reconsider their previous answers in the light of the aggregated group's response, and to revise them or comment upon them if they felt this was appropriate. Of the 46 participants, 45 completed the two rounds of the survey. A total of $41 \%$ of participants changed at least one score during Round 2, although only $14 \%$ of scores were changed, which is less than the rule of thumb proposed by Nelson that stability is reached when fewer than $20 \%$ of individual participants' responses have changed (Nelson 1978, cited in Novakowski and Wellar 2008). Once all responses to Round 2 had been received, the results were 
analyzed and, since it was clear that stability in responses had been reached, participants were informed that the survey had been completed and asked whether they were willing to have their names identified.

Two alternative designs were presented to the 10 research colleagues who agreed to participate in the pilot phase of the survey: the full profile design that came to be used whereby all 60 forest stand types were included in the matrix, and a reduced design whereby respondents were asked to score 16 forest stand types selected to represent sufficient combinations of attributes so that all other combinations could be calculated using conjoint analysis. Typically a researcher seeks to reduce the combinations of attributes, and levels of attributes, to optimize the number of evaluation situations presented to the respondent so that they are not overburdened (Alriksson and Öberg 2008). However, it has also been argued that a full design can give a more realistic choice situation allowing researchers to model actual choices (Herrmann et al. 2003). In practice, during the pilot phase respondents found the reduced design very difficult to complete. The full design was also challenging but simpler to complete, because of the contextual information inherent in the design of the scoresheet. Respondents could take into account the position of each cell in relation to the three axes that together defined each stand type, allowing for adjustments until the scores fitted their understanding of the contributions of the three attributes.

Overall, 93 points were raised in survey participants' comments regarding the process of scoring forest stand types. Around half of these points (47) were explanations for individual's scores, 22 points raised issues regarding the conceptual framework that was used, 12 points highlighted difficulties experienced in completing the exercise, seven points highlighted that forest stands had been taken out of context making the process more difficult and the results less valid, while five points raised similar concerns about the requirement to respond on behalf of the average visitor (Edwards et al. 2010a).

\section{Analysis of data}

For each forest stand type, the median values from Round 2 in each region represented the recreational scores that are analyzed here, and used for European scenario analysis (UNECE/FAO 2011, M.-J. Schelhaas, M. Didion, E. Arets, D. Edwards, G. Hengeveld, M. Lindner, B. Mason, A. Moiseyev, G.-J. Nabuurs unpublished manuscript). For this latter purpose, a European dataset was generated by transferring the scores to each country from the region that it most closely resembled in biophysical terms.

The data were explored using conjoint analysis, a decompositional stated preference method that can be used to estimate the preference each respondent has for each attribute of a situation. Respondents are presented with a number of situations that vary according to the levels of each attribute, and are then asked to evaluate each one, typically by ranking or rating. Their responses are then decomposed to calculate the importance weightings, or utility factors, for each attribute (Alriksson and Öberg 2008). Conjoint analysis was used here to show the relative importance to the recreational value of forests of: (1) the three attributes, and (2) each level or component of the three attributes. A multivariate analysis of variance (MANOVA) was carried out on the importance weightings for each region to test whether there were differences in importance across the four regions. All analyses were undertaken using the statistical software SAS 9.2 (SAS Institute Inc. 2008).

\section{RESULTS}

The recreational scores (i.e., the median values from Round 2 for each forest stand type in each region are given in Table 1. Examination of the table reveals that scores tended to be highest for adult phase forest nature reserves and close-tonature forestry (FMA1 and 2) and lowest for establishment phase wood biomass production (FMA5), suggesting that recreational value was seen by many participants to increase with both the age and, to a lesser extent, decrease with the management intensity of the stand. Tree species type had a relatively small impact on the scores for any given region.

\section{Relative importance of each attribute}

The mean relative importance of each of the three attributes in each region calculated by conjoint analysis is expressed as a percentage in Table 2. Multivariate analysis of variance (MANOVA) showed that there was a significant difference between the regions ( $p<0.01$; see Appendix 1 for the individual utilities derived from the analysis). The results indicate that, in all four regions, phase of development was the most important, and species type was the least important, of the three attributes in explaining the recreational scores assigned to the forest stand types. For Great Britain, the importance of phase of development was around twice that of species type, while FMA was of slightly lower importance than phase of development. For the Nordic region, phase of development was seen as eight times as important as species type and more than twice that of FMA. The results of the Central Europe panel resembled those of Great Britain, although species type was of relatively lower importance than for Great Britain. For the Iberia panel, phase of development was around three times as important as species type, while FMA lay approximately halfway in importance between phase of development and tree species type.

\section{Relative importance of the levels of attributes}

Figures 1 to 3 show the relative importance or contribution to recreational value of each FMA, phase of development, and tree species type in each region, or in other words, the effect of an increase in the level of each attribute on the recreational value of forests in each region (see Appendix 1 for individual utility values). 
Table 2. Mean importance and standard error of forest management alternative (FMA), phase of development, and tree species type, by region.

\begin{tabular}{|c|c|c|c|c|c|c|}
\hline \multirow[b]{2}{*}{ Region } & \multicolumn{3}{|c|}{$\begin{array}{c}\text { Mean importance } \\
\text { (percentage) }\end{array}$} & \multicolumn{3}{|c|}{$\begin{array}{l}\text { Mean importance } \\
\text { (standard error) }\end{array}$} \\
\hline & FMA & $\begin{array}{c}\text { Phase of } \\
\text { development }\end{array}$ & $\begin{array}{c}\text { Tree species } \\
\text { type }\end{array}$ & FMA & $\begin{array}{c}\text { Phase of } \\
\text { development }\end{array}$ & $\begin{array}{c}\text { Tree species } \\
\text { type }\end{array}$ \\
\hline Great Britain $(n=10)$ & 37 & 41 & 23 & 4.8 & 5.1 & 4.3 \\
\hline Nordic Region $(n=12)$ & 28 & 65 & 8 & 2.0 & 2.0 & 1.5 \\
\hline Central Europe $(n=13)$ & 38 & 45 & 17 & 2.7 & 3.4 & 1.7 \\
\hline Iberia $(n=10)$ & 35 & 50 & 15 & 3.1 & 4.2 & 2.5 \\
\hline
\end{tabular}

Regarding FMAs, Figure 1 indicates that the relationship between management intensity and recreational value is bellshaped or s-shaped. In all regions, wood biomass production (FMA5) had the lowest contribution to recreational value. In Great Britain and Central Europe, forest nature reserves and close-to-nature forestry (FMA1 and 2) were both of approximately equal importance and there was a stepwise decrease in contributions from close-to-nature forestry to wood biomass production (FMA5). However, in Iberia, close-tonature forestry had the highest contribution, while in the Nordic Region combined objective forestry (FMA3) had the highest contribution. Regarding phase of development, Figure 2 shows that there was a steep increase in contribution from establishment to adult phase for all regions. Figure 3 indicates that the differences between tree species types were relatively small in all regions showing that this attribute had a minor influence on recreational value of forests. Conifer stands had the lowest contribution, while mixed stands had the highest contribution except in Great Britain where broadleaved stands had a slightly higher contribution than mixed stands.

Fig. 1. Contribution of forest management alternatives (FMA) to recreational score, by region. The five FMAs are: (1) forest nature reserves; (2) close-to-nature forestry; (3) combined objective forestry; (4) intensive, even-aged forestry, and (5) woody biomass production.

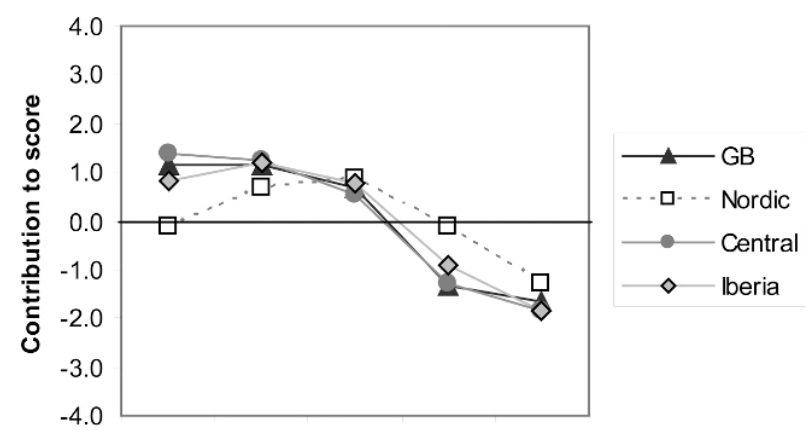

FMA 1 FMA 2 FMA 3 FMA 4 FMA 5
Fig. 2. Contribution of phases of development to recreational score, by region

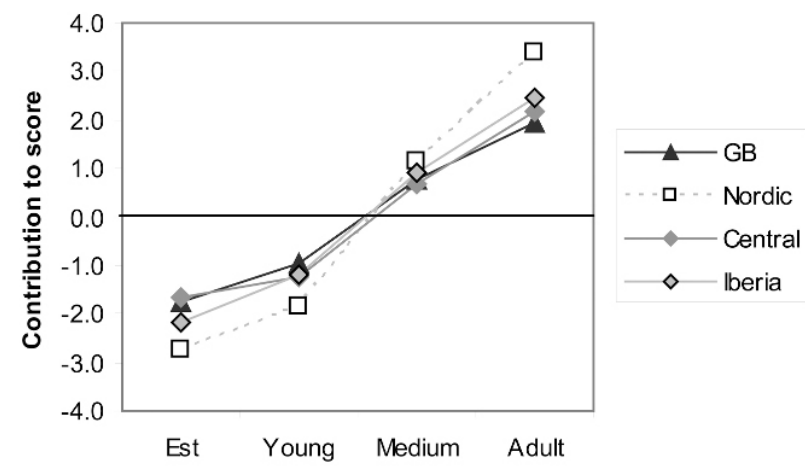

Fig. 3. Contribution of tree species type to recreational score, by region

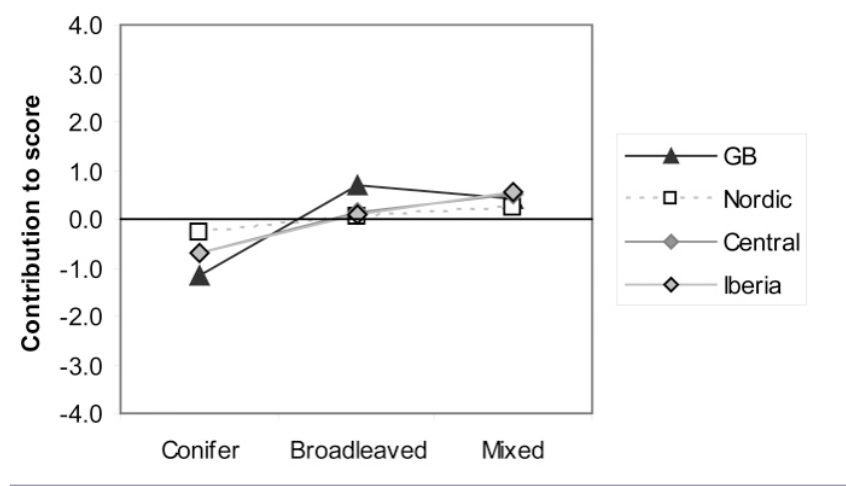




\section{DISCUSSION}

\section{Methodological issues}

Survey design

The use of experts in a Delphi process, conducted over successive rounds, has recognized strengths and weaknesses (Landeta 2006, Novakowski and Wellar 2008). A review by Landeta reports several potential methodological problems including those associated with the definition and recruitment of experts and the biases that experts may have, the limited and controlled nature of the interaction with participants, the scope for irresponsible actions by participants acting anonymously and for "interested manipulation" by those running the survey, the difficulty of checking the accuracy of the results, and the time and effort required to participate in the process (Landeta 2006:469). Nevertheless, if the method is followed rigorously it is seen to generate valid data at much lower cost than standard questionnaire surveys using larger samples of subjects (Landeta 2006).

In our study, the reliability and validity of the results could have been enhanced by employing a psychophysical survey whereby images of each forest stand type are scored by individuals from representative samples of the population in each region (e.g., Brown and Daniel 1984, Jensen and Koch 1998, Blasco et al. 2009), but given the broad scope of the study this option was prohibitively expensive. Instead, the use of a conceptual framework of forest stand types greatly reduced the resources required for data collection, but necessitated the participation of experts who were able to imagine each stand type, and score it on behalf of the average visitor, on the basis of their professional knowledge and experience. The decision to run the survey over successive rounds provided participants with the opportunity to revise their scores, but in practice this made little difference to the median scores obtained for each forest stand type. Also, few new points were raised in the comments during Round 2. In retrospect, given the extra work required by both researchers and participants, the survey could have been carried out more efficiently as a simple questionnaire administered in a single round to individual experts in each region, although with a small loss in the accuracy of the results.

The utility values derived through conjoint analysis are dependent upon the precise elicitation format presented in the questionnaire (Alriksson and Öberg 2008). As mentioned in the Methods section, during the pilot phase a full design was demonstrated to be easier to complete than a partial design. Despite this choice of design, when the survey was implemented, several participants reported difficulties in completing the task, although only one participant did not do so. The instruction to use the full ten-point scale was not obvious to some participants who were later asked to adjust their scores accordingly. This instruction was given to reduce the variation between participants in their use of the ten-point scale whereby some individuals mark generously, using the top end of the scale, and vice versa. Definitions of forest stand types

The selection of tree species and geographical regions represented a compromise between realistic definitions of forest stand types and applicability of scores over a wider geographical area. Given the scope of the study, the most pragmatic solution was to focus on the commonest tree species within broadly defined regions. This decision raised concerns among several participants about some of the forest stand type definitions. The choice of Sitka spruce was questioned by participants in the Great Britain panel, since it is an introduced species, and strictly speaking would not be found in forest nature reserves (FMA1). However, the species does exist in a few old growth stands that structurally resemble forest nature reserves, and we argue that they could be classified as FMA1 for the purposes of this study, which is concerned with recreational rather than biodiversity values. During Round 1, several participants challenged the existence of adult phase wood biomass production (FMA5), given the definitions of rotations provided in the questionnaire. Accordingly it was removed from Round 2, and no scores have been reported in Table 1. Similar points were raised about establishment phase forest nature reserves (FMA1), but it was decided that it does exist as a forest stand type even if it occurs rarely. Absence of context

A number of points were raised in all regions regarding the difficulties in visualizing and scoring forest stand types when taken out of context. The surrounding landscape, and the geographical location of the stand, can influence its value. Such effects have been highlighted by several other studies (Axelsson-Lindgren and Sorte 1987, Jensen and Koch 1998, Schraml and Volz 2009). In Central Europe, one respondent noted that, in Switzerland, Norway spruce was only appreciated by the public in higher altitude locations, where it is considered to be a natural component of the landscape. In the Nordic Region and Iberia, the size of the stand was seen as a factor that influenced whether establishment phase made a positive or negative contribution to the overall recreational value of the forest, with small stands offering the visitor a welcome break in forest cover and large stands seen as intrusive interventions.

A related concern was with the notion of an "average visitor", which was seen to be difficult to conceptualize. Most forest preference research disaggregates its findings according to social categories such as gender, age, and ethnicity (e.g., Pukkala et al. 1988, Blasco et al. 2009). While differences in preferences between these categories are often demonstrated, it is rarely possible to generalize beyond the case study area, or indeed to the pan-European scale adopted by this study. Thus, we argue that the quality of the results would not have 
been improved by asking participants to disaggregate between social categories. It is possible that individuals pursuing specialist recreational activities such as hunting, berry picking or mountain biking have consistently different preferences for the structural attributes of forests, and respondents were asked to take these differences into account when conceiving of the average visitor. However, we judged that in most locations a substantial majority of visitors to forests are likely to be walkers for whom visual attractiveness is more important in determining the recreational value of a forest stand than those factors that only enhance its suitability for more specialist activities (Edwards et al. 2011, Edwards et al., in press).

\section{Interpretation of results}

Phase of development

Our finding that phase of development is of the highest importance, and has a consistently positive relationship to recreational value, is supported by the results of our companion study of 12 attributes of forests, conducted as part of the same Delphi survey (Edwards et al. 2010b, Edwards et al., in press), where the attribute "size of trees within stand" was ranked the most important overall, with small regional differences, and its relationship was judged to be positive, that is, an increase in size of trees increased recreational value. The positive relationship was also widely supported by participants' comments, although some participants from the Nordic Region and Central Europe queried the consensus on the low value attached to establishment phase since it may provide attractive views over surrounding more mature forested land (cf. Edwards et al. 2011). The literature on forest preferences also supports these findings. Size of trees appears to be the quality with the most important and generalizable link to recreational value, with larger trees being preferred (Gundersen and Frivold 2008, Ribe 1989). Tree species type

Our finding that tree species type was of relatively little importance, and that, on balance, broadleaves are marginally preferable to conifers, while mixed stands are marginally preferable to monocultures, is also supported by Edwards et al. (in press), where the attribute "number of tree species" was considered relatively unimportant overall, and assigned a positive relationship to recreational value by only a small majority of participants. Most of the participants' comments also support this finding, for example, one respondent from Central Europe wrote: “....a preference of beech over spruce probably exists in my region, but I guess it is restricted to the summer aspect; in wintertime probably the preference changes, so in sum over the whole year there may not be very big differences. However, mixed forests are probably preferred even in wintertime (they show the aesthetical advantages of both conifers and deciduous trees)." A slight preference for mixed stands over monocultures, and broadleaved over conifer, was also apparent from the literature review conducted by Ribe (1989), although Gundersen and Frivold's (2008) review of the
Fennoscandian literature presents a more complex contextspecific picture (cf. Lee 2001, Willis et al. 2003, Schraml and Volz 2009). Forest Management Alternative

No single attribute was selected by Edwards et al. (in press) to represent management intensity because this quality was seen to comprise a combination of several other attributes that were included in the study, in particular, size of trees, variation in tree size, variation in tree spacing, number of tree species, and variation between stands. Not all of these attributes were assigned a linear positive relationship to recreational value by participants; in some cases it was bell-shaped (Edwards et al., in press). This provides some support for the bell-shaped or s-shaped relationship between FMA and recreational value in different regions reported here. Responses from the Nordic Region differed most from the other regions, with the greatest preference shown for combined objective forestry (FMA3). The low preference for forest nature reserves (FMA1) was explained by one participant: “...we know that Finnish people in general do not like dead trees and that the unmanaged forest is in most cases too dense..." Another stated that: "Sometimes forest nature reserves have been perceived as confused sceneries among recreationists due to the dead wood and fallen trees." Similar points were made by participants from Central Europe and to a lesser extent from Iberia, but not from Great Britain.

On preferences for management intensity, the review by Ribe (1989:59) was inconclusive: "All these findings together suggest that there is no clear and simple aesthetic dichotomy between managed and unmanaged forests, except when management creates heavy disturbances." However, a household survey of forest preferences in Great Britain by Lee (2001) suggests a preference for forest nature reserves and close-to-nature forestry (FMA1 and 2), which supports our findings for the Great Britain panel (cf. Filyushkina 2010). Several authors in mainland Europe highlighted a preference for close-to-nature forests (e.g., Schraml and Volz 2009) although it is not clear whether this forest type had been distinguished from forest nature reserves (cf. Scrinzi and Floris 2000, Rametsteiner and Kraxner 2003). Overall, the consensus appears to be that a low level of management intensity is valued most, but that a degree of intervention is preferred to "tidy up" the forest landscape allowing moderate visual penetration or by removing deadwood, even if many recreational users may not be fully aware that the forests they prefer are not entirely "natural" (Jensen 1999). The available literature does not allow clear differentiation between European regions, although some evidence can be found to support the regional differences suggested by the Delphi survey, for example in Great Britain.

\section{CONCLUSION}

This study is the first to provide indicative scores, elicited through expert consultation, for the recreational value of a 
comprehensive range of forest types at a European scale. Perhaps the most important finding concerns the relationship between the intensity of management and recreational value, which indicates the extent to which forest visitors in different regions of Europe prefer forests with a small but significant degree of intervention to "tidy up" the stand as opposed to a situation with no management at all. This preference was clearest in the Nordic Region where combined objective forestry (FMA3) was most preferred, i.e., the forest management alternative that lies midway along the continuum of management intensity used in the study.

Across Europe, phase of development was shown to make the largest contribution to recreational value, and tree species type the smallest contribution (cf. Edwards et al., in press). This latter finding suggests that criticism directed towards conifers, and perceived preferences for broadleaves, in many parts of Europe, may not be due to the choice of tree species per se, but the use of conifers in intensive management regimes or geometric forest designs within the wider landscape that are judged poorly from a visual or recreational perspective (cf. Price 2003). The findings provide managers and policy makers with evidence to support long-term retention of forest stands, and conversion of intensively managed forests to continuous cover forestry and other low-impact silvicultural systems, in which recreation is an important management goal.

These headline findings are supported by the literature on forest preference research, although it is acknowledged that they may hide substantial variation in preferences between individuals and social groups within any given region. It is important to stress that the results are indicative. The use of a Delphi approach was necessary to carry out a survey on such a large scale with limited resources, but there are weaknesses in the approach (Landeta 2006). More robust data could be obtained with a psychophysical survey that uses images instead of descriptions for each forest stand type, and a larger sample of forest visitors in each region. As it stands, the study presents new evidence on the relationship of management intensity of forests to recreational value across Europe as a basis for further comparative research, as well as providing for the first time a dataset for modeling the impacts of forest-related policies on the recreational value of forests in Europe (UNECE/FAO 2011, M.-J. Schelhaas, M. Didion, E. Arets, D. Edwards, G. Hengeveld, M. Lindner, B. Mason, A. Moiseyev, G.-J. Nabuurs unpublished manuscript).

Responses to this article can be read online at:

http://www.ecologyandsociety.org/voll7/iss1/art27/responses/

\section{Acknowledgments:}

The authors would like to thank the participants in the Delphi survey reported in this paper: Great Britain: Simon Bell, Mike
Christie, Guy Garrod, Max Hislop, Iona Hyde, Anna Lawrence, Alister Scott, Nicholas Shepherd, Bill Slee, and Ken Willis. Nordic Region: Mattias Boman, Lars Helge Frivold, Vegard Gundersen, Sven-G Hultman, Eeva Karjalainen, Minna Komulainen, Anders Lindhagen, Irja Löfström, Eija Pouta, Dan Rydberg, Tuija Sievänen, and Per Wallsten. Central Europe: Arne Arnberger, Andreas Bernasconi, Matthias Buchecker, Peter Elsasser, Erwin Frohmann, Ralf Hansmann, Marcel Hunziker, Florian Kraxner, Gerd Lupp, Carsten Mann, Andreas Muhar, Ulrike Pröbstl, Stephan WildEck, and Veronika Wirth. Iberia: José G. Borges, Raul Brey, Alejandro Caparrós Gass, Gloria Domínguez Torres, Francois Lefevre, Livia Madureira, Robert Mavsar, Nicolas Robert, Eduardo Rojas Briales, and Cristina Vega García. We also thank Jean-Michel Carnus, Jose Manuel Gonzalez, Geerten Hengeveld, Hervé Jactel, Bill Mason, Stefania Pizzirani, Mart-Jan Schelhaas, Mike Smith, and Phillip Taylor. The research was carried out as part of EFORWOOD, and co-funded by the European Commission's 6th Framework Programme, and the Forestry Commission, Great Britain.

\section{LITERATURE CITED}

Alriksson, S., and T. Öberg. 2008. Conjoint analysis for environmental evaluation: a review of methods and applications. Environmental Science \& Pollution Research 15 (3):244-257. http://dx.doi.org/10.1065/espr2008.02.479

Arnberger, A., T. Aikoh, R. Eder, Y. Shoji, and T. Mieno. 2010. How many people should be in the urban forest? A comparison of trail preferences of Vienna and Sapporo forest visitor segments. Urban Forestry and Urban Greening 9:215-225. http://dx.doi.org/10.1016/j.ufug.2010.01.002

Axelsson-Lindgren, C., and G. Sorte. 1987. Public responses to differences between visually distinguishable forest stands in a recreation area. Landscape and Urban Planning 14:211-217. http://dx.doi.org/10.1016/0169-2046(87)90030-2

Blasco, E., J. R. González-Olabarria, P. Rodriquez-Veiga, T. Pukkala, O. Kolhemainen, and M. Palahí. 2009. Predicting scenic beauty of forest stands in Catalonia (North-east Spain) Journal of Forestry Research 20(1):73-78. http://dx.doi.org/1 0.1007/s11676-009-0013-3

Brown, T. C., and T. C. Daniel. 1984. Modeling forest scenic beauty: concepts and application to Ponderosa Pine. USDA Forest Service Research Paper RM-256. Rocky Mountain Forest and Range Experiment Station, Fort Collins, Colorado, USA.

Duncker, P. H., S. Barreiro, G. Hengeveld, T. Lind, W. Mason, S. Ambrozy, and H. Spiecker. in press. Classification of Forest Management Approaches: a new methodological framework and its applicability to European forestry. Ecology and Society. 
Edwards, D., M. Jay, F. S. Jensen, B. Lucas, M. Marzano, C. Montagne, A. Peace, and G. Weiss. 2010a. Assessment of the recreational value of European forest management alternatives. EFORWOOD Report D2.3.6, Forest Research, UK. [online] URL: http://www.forestry.gov.uk/pdf/EFORWOOD D2 36 Assessment of the recreational value of European_FMAs_F INAL_060810.pdf/\$FILE/EFORWOOD_D2_3_6_Assessmen $\mathrm{t}$ of the recreational value of European FMAs FINAL 060810. pdf

Edwards, D., M. Jay, F. S. Jensen, B. Lucas, M. Marzano, C. Montagne, A. Peace, and G. Weiss. 2010b. Public preferences for silvicultural attributes of European forests. EFORWOOD Report D2.3.3, Forest Research, UK. [online] URL: http://www .forestry.gov.uk/pdf/EFORWOOD D2 33 Public preferenc es for silvicultural attributes of European forests FINAL 060810. pdf/\$FILE/EFORWOOD D2 33 Public preferences for sil vicultural attributes of European forests FINAL 060810.pdf

Edwards, D., M. Jay, F. S. Jensen, B. Lucas, M. Marzano, C. Montagne, A. Peace, and G. Weiss. In press. Public preferences for structural attributes of forests: towards a pan-European perspective. Forest Policy and Economics.

Edwards, D., F. S. Jensen, M. Marzano, B. Mason, S. Pizzirani, and M.-J. Shelhaas. 2011b. A theoretical framework to assess the impacts of forest management on the recreational value of European forests. Ecological Indicators 11:81-89. http://dx.doi. org/10.1016/j.ecolind.2009.06.006

Filyushkina, A. 2010. Continuous cover forestry and preferences of recreationists: implications for forest management in North Wales. Thesis. Bangor University, Wales, UK.

Gundersen, V. S., and L. H. Frivold. 2008. Public preferences for forest structures: a review of quantitative surveys from Finland, Norway and Sweden. Urban Forestry and Urban Greening 7:241-258. http://dx.doi.org/10.1016/j.ufug.2008.05.001

Herrmann, A., D. Schmidt-Gallas, and F. Huber. 2003. Adaptive conjoint analysis: understanding the methodology and assessing reliability and validity. Pages 253-278 in A. Gustafsson, A. Herrmann, and F. Huber, editors. Conjoint measurement methods and applications. Springer Verlag, Berlin, Germany.

Hill, G., P. Courtney, R. Burton, and J. Potts. 2003. Forests' role in tourism: Phase 2. Report to Forestry Commission. The Macaulay Institute, Edinburgh, UK.

Jensen, F. S. 1999. Forest recreation in Denmark from the 1970 s to the 1990s. The Research Series, Vol 26. Danish Forest and Landscape Research Institute, Hørsholm, Denmark.

Jensen, F. S., and N. E. Koch. 1998. Measuring forest preferences of the population; a Danish approach. Pages 39-82 in D. Terrasson, editor. Public perception and attitudes of forest owners towards forest in Europe. Perception publique et attitudes des propriétaires envers la forêt en Europe. Commentaires et synthèses du groupe de travail COST E3WG1, 1994/1998. Cemagref éditions, Antony cedex, France. http://dx.doi.org/10.3188/szf.2000.0011

Landeta, J. 2006. Current validity of the Delphi method in social sciences. Technological Forecasting and Social Change 73:467-482. http://dx.doi.org/10.1016/j.techfore.2005.09.002

Lee, T. R. 2001. Perceptions, attitudes and preferences in forests and woodlands. Technical Paper 18, Forestry Commission, Edinburgh, UK.

Linstone, H. A., and M. Turoff, editors. 1975. The Delphi method: techniques and applications. Addison Wesley, Boston, MA, USA.

Nelson, B. 1978. Statistical manipulation of delphi statements: its success and effects on convergence and stability. Technological Forecasting and Social Change 12:41-60. http ://dx.doi.org/10.1016/0040-1625(78)90034-3

Novakowski, N., and B. Wellar. 2008. Using the Delphi technique in normative planning research: methodological design considerations. Environment and Planning A 40:1485-1500.

Price, C. 2003. Quantifying the aesthetic benefits of urban forestry. Urban Forestry and Urban Greening 1:123-133. http://dx.doi.org/10.1078/1618-8667-00013

Pröbstl, U., B. Elands, and V. Wirth. 2009. Forest recreation and nature tourism in Europe: context, history and current situation. Pages 12-32 in S. Bell, M. Simpson, L. Tyrväinen, T. Sievänen, and U. Pröbstl, editors. European forest recreation and tourism: a handbook. Taylor and Francis, UK.

Pukkala, T., S. Kellomäki, and E. Mustonen. 1988. Prediction of the amenity of a tree stand. Scandanavian Journal of Forest Research 3:533-544. http://dx.doi.org/10.1080/02827588809 $\underline{382538}$

Rametsteiner, E., and F. Kraxner. 2003. Europeans and their forests: what do Europeans think about forests and sustainable forest management? Ministerial Conference on the Protection of Forests in Europe (MCPFE) Liaison Unit, Vienna, Austria.

Ribe, R. G. 1989. The aesthetics of forestry: what has empirical preference research taught us? Environmental Management 13:55-74. http://dx.doi.org/10.1007/BF01867587

SAS Institute Inc. 2008. SAS/STAT 9.2 Users guide. SAS Institute Inc., Cary, North Carolina, USA.

Schraml, U., and K.-R.Volz. 2009. Do species matter? Valuable broadleaves as an object of public perception and 
policy. Pages 213-236 in H. Spiecker, editor. Valuable broadleaved forests in Europe. S. Brill, Leiden, The Netherlands; Boston, USA, Köln, Germany.

Scrinzi, G., and A. Floris. 2000. Featuring and modelling forest recreation in Italy. Forestry 73:173-185. http://dx.doi.org/10.1 $\underline{093 / \text { forestry/73.2.173 }}$

Silvennoinen, H., J. Alho, O. Kolehmainen, and T. Pukkala. 2001. Prediction models of landscape preferences at the forest stand level. Landscape and Urban Planning 56:11-20. http://d x.doi.org/10.1016/S0169-2046(01)00163-3

Tyrväinen, L., S. Pauleit, K. Seeland, and S. Vries. 2005. Benefits and uses of urban forests and trees. Pages 81-114 in C. C. Konijnendijk, K. Nilsson, T. B. Randrup, and J. Schipperijn, editors. Urban forests and trees. Springer-Verlag, Berlin, Heidelberg, Germany. http://dx.doi.org/10.1007/3-540-27684$\underline{\times} 5$

UNECE/FAO (United Nations Economic Commission for Europe/ Food and Agriculture Organization of the United Nations). 2011. The European forest sector outlook study II: 2010-2030. UNECE, Geneva, Switzerland and FAO, Rome, Italy.

Willis, K., G. Garrod, R. Scarpa, N. Powe, A. Lovett, I. Bateman, $\mathrm{N}$. Hanley, and D. Macmillan, editors. The social and environmental benefits of forestry in Great Britain, Phase 2. Centre for Research in Environmental Appraisal and Management, University of Newcastle, UK. [online] URL: htt p://www.forestry.gov.uk/forestry/ahen-5hzcbh

Zandersen, M., and R. S. J. Tol. 2009. A meta-analysis of forest recreation values in Europe. Journal of Forest Economics 15 (1-2):109-130. http://dx.doi.org/10.1016/j.jfe.2008.03.006

Zube, E. H., J. L. Sell, and J. G. Taylor. 1982. Landscape perception: research, application and theory. Landscape Planning 9:1-33. http://dx.doi.org/10.1016/0304-3924(82)90009-0 
Appendix 1. Utilities from individual conjoint analyses of each attribute level within each region

\begin{tabular}{|c|c|c|c|c|c|c|c|c|c|c|c|c|c|}
\hline \multirow{2}{*}{ ID } & \multirow{2}{*}{$\begin{array}{l}\text { Inter } \\
\text {-cept }\end{array}$} & \multicolumn{5}{|c|}{ Forest man agement a ltern ative } & \multicolumn{4}{|c|}{ Phase of development } & \multicolumn{3}{|c|}{ Tree species type } \\
\hline & & 1 & 2 & 3 & 4 & 5 & $\mathbf{E}$ & $\mathbf{Y}$ & $M$ & A & Con & & Mix \\
\hline \multicolumn{14}{|c|}{ G reat B ritain } \\
\hline 1 & 5.00 & 1.50 & 1.00 & -0.00 & -0.83 & -1.67 & -3.00 & -1.67 & 1.33 & 3.33 & -0.49 & 0.56 & -0.07 \\
\hline 2 & 5.36 & 2.14 & 2.14 & 0.72 & -1.94 & -3.07 & -0.69 & 0.31 & 0.17 & 0.21 & -1.72 & 1.60 & 0.12 \\
\hline 3 & 4.15 & 1.18 & 0.51 & -0.23 & -0.65 & -0.82 & -1.88 & -0.75 & 0.65 & 1.98 & -1.14 & 1.17 & -0.03 \\
\hline 4 & 5.50 & 1.58 & 1.75 & 1.75 & -2.00 & -3.09 & -1.50 & -0.76 & 0.70 & 1.56 & -0.32 & -0.42 & 0.74 \\
\hline 5 & 4.53 & 0.55 & 1.13 & 0.88 & -0.61 & -1.96 & -2.06 & -1.53 & 1.20 & 2.40 & -1.09 & 0.44 & 0.65 \\
\hline 6 & 4.84 & 1.07 & 0.91 & 0.82 & -0.84 & -1.96 & -2.18 & -1.31 & 0.49 & 3.00 & -1.42 & 0.68 & 0.74 \\
\hline 7 & 6.06 & -0.47 & -0.31 & 1.44 & -1.22 & 0.56 & -0.86 & -0.46 & 0.81 & 0.50 & -2.89 & 1.47 & 1.42 \\
\hline 8 & 4.54 & 0.71 & 0.80 & 0.46 & -0.62 & -1.36 & -2.00 & -0.87 & 0.66 & 2.21 & -1.12 & 1.09 & 0.03 \\
\hline 9 & 5.36 & 0.89 & 0.56 & 0.39 & -0.94 & -0.91 & -1.89 & -1.69 & 0.91 & 2.67 & -1.21 & 0.53 & 0.68 \\
\hline 10 & 4.46 & 2.20 & 2.78 & 0.70 & -3.46 & -2.22 & -1.66 & -0.66 & 0.93 & 1.40 & -0.09 & 0.07 & 0.02 \\
\hline A v & 4.98 & 1.14 & 1.13 & 0.69 & -1.31 & -1.65 & -1.77 & -0.94 & 0.79 & 1.93 & -1.15 & 0.72 & 0.43 \\
\hline \multicolumn{14}{|c|}{ Nordic R egion } \\
\hline 1 & 5.54 & -0.20 & 2.46 & 0.55 & -0.72 & -2.09 & -2.73 & -1.34 & 1.06 & 3.01 & -0.01 & -0.01 & 0.03 \\
\hline 2 & 4.51 & -0.42 & 1.66 & 1.24 & -0.49 & -1.98 & -2.04 & -2.51 & 0.98 & 3.57 & -0.00 & -0.32 & 0.32 \\
\hline 3 & 4.55 & -0.89 & -0.22 & 0.94 & 0.14 & 0.02 & -2.42 & -1.22 & 0.25 & 3.39 & -0.06 & -0.11 & 0.17 \\
\hline 4 & 3.66 & -0.74 & -0.41 & 0.84 & 0.23 & 0.08 & -2.66 & -2.59 & 1.38 & 3.87 & -0.40 & 0.08 & 0.32 \\
\hline 5 & 5.07 & 0.18 & 0.43 & 1.18 & -0.01 & -1.78 & -3.40 & -2.14 & 2.00 & 3.54 & -0.29 & 0.29 & 0.01 \\
\hline 6 & 5.93 & 0.49 & 1.07 & 0.65 & -0.10 & -2.11 & -3.46 & -1.80 & 2.14 & 3.12 & -0.93 & -0.09 & 1.02 \\
\hline 7 & 4.08 & -1.08 & -0.50 & 1.67 & 1.00 & -1.08 & -1.48 & -2.48 & 0.62 & 3.34 & -0.12 & 0.19 & -0.07 \\
\hline 8 & 4.98 & -0.23 & 1.35 & 0.68 & -0.50 & -1.29 & -2.98 & -1.32 & 0.89 & 3.41 & 0.02 & 0.23 & -0.25 \\
\hline 9 & 4.89 & -0.06 & 0.78 & 0.28 & 0.04 & -1.03 & -3.09 & -1.49 & 1.35 & 3.23 & -0.51 & 0.17 & 0.34 \\
\hline 10 & 4.12 & -0.12 & -0.04 & 1.38 & 0.27 & -1.48 & -2.59 & -2.12 & 0.80 & 3.91 & 0.48 & -0.10 & -0.38 \\
\hline 11 & 4.86 & 0.31 & 0.47 & 0.97 & 0.00 & -1.76 & -2.59 & -1.19 & 0.81 & 2.97 & -1.16 & 0.73 & 0.43 \\
\hline 12 & 4.44 & 1.14 & 0.97 & -0.03 & -1.03 & -1.06 & -3.31 & -1.78 & 1 & 3.49 & -0.21 & -0.31 & 0.52 \\
\hline Av & 4.72 & -0.14 & 0.67 & 0.86 & -0.10 & -1.30 & -2.73 & -1.83 & 1.16 & 3.40 & -0.27 & 0.06 & 0.21 \\
\hline \multicolumn{14}{|c|}{ C entral E urope } \\
\hline 1 & 5.19 & 1.80 & 1.64 & 0.31 & -1.61 & -2.14 & -1.73 & -0.59 & 0.63 & 1.69 & -1.06 & 0.86 & 0.20 \\
\hline 2 & 4.89 & 1.86 & 1.94 & 0.02 & -1.64 & -2.18 & -2.16 & -0.96 & 0.72 & 2.40 & -0.35 & -0.41 & 0.76 \\
\hline 3 & 4.78 & 1.97 & 1.22 & -0.03 & -1.28 & -1.90 & -1.91 & -1.11 & 0.77 & 2.25 & -0.92 & 0.35 & 0.57 \\
\hline 4 & 4.42 & 0.75 & 1.25 & 1.00 & -0.92 & -2.09 & -0.08 & -2.82 & 1.09 & 1.81 & -0.69 & -0.26 & 0.98 \\
\hline 5 & 5.31 & 2.77 & 1.85 & 0.93 & -2.06 & -3.49 & -1.11 & -0.65 & 0.37 & 1.40 & -0.85 & 0.73 & 0.12 \\
\hline 6 & 4.30 & 1.45 & 0.62 & 0.45 & -1.13 & -1.39 & -1.37 & -0.83 & 0.09 & 2.10 & 0.11 & -0.55 & 0.45 \\
\hline 7 & 4.92 & 1.49 & 0.66 & -0.01 & -1.01 & -1.14 & -2.26 & -0.59 & 0.97 & 1.87 & -0.88 & 0.16 & 0.72 \\
\hline 8 & 5.50 & 0.25 & 0.42 & 1.42 & -0.41 & -1.68 & -1.76 & -1.56 & 0.83 & 2.5 & 0.44 & 0.06 & -0.50 \\
\hline 9 & 4.09 & 1.41 & 1.08 & 0.08 & -1.09 & -1.48 & -1.29 & -1.69 & 0.52 & 2.46 & -0.88 & 0.08 & 0.80 \\
\hline 10 & 5.02 & 1.31 & 1.41 & 0.47 & -1.19 & -1.73 & -1.69 & -1.22 & 0.54 & 2.37 & -0.83 & 0.39 & 0.44 \\
\hline 11 & 4.59 & 0.08 & 0.91 & 0.83 & -0.92 & -0.90 & -3.19 & -2.59 & 1.59 & 4.19 & -0.04 & -0.37 & 0.41 \\
\hline 12 & 4.86 & 0.23 & 1.39 & 1.39 & -1.52 & -1.49 & -1.39 & -0.79 & 0.33 & 1.85 & -1.36 & -0.01 & 1.38 \\
\hline 13 & 5.37 & 2.46 & 1.80 & 0.05 & -1.70 & -2.60 & -1.37 & -0.77 & 0.58 & 1.56 & -1.53 & 1.07 & 0.46 \\
\hline Av & 4.86 & 1.37 & 1.25 & 0.53 & -1.27 & -1.86 & -1.64 & -1.24 & 0.69 & 2.19 & -0.68 & 0.16 & 0.52 \\
\hline \multicolumn{14}{|c|}{ Iberia } \\
\hline 1 & 4.17 & -0.67 & 1.16 & 1.57 & -0.92 & -1.13 & -1.91 & -1.37 & 0.49 & 2.79 & -0.88 & 0.86 & 0.02 \\
\hline 2 & 4.36 & 1.39 & 0.89 & -0.11 & -0.77 & -1.40 & -1.56 & -0.82 & 0.84 & 1.54 & -1.35 & -0.19 & 1.54 \\
\hline 3 & 4.60 & 2.40 & 1.99 & 0.24 & -1.85 & -2.78 & -2.60 & -0.73 & 0.87 & 2.46 & -0.25 & -0.25 & 0.49 \\
\hline 4 & 6.77 & 0.90 & 0.90 & 0.90 & -1.43 & -1.27 & -2.23 & -0.63 & 0.70 & 2.17 & -0.77 & 0.39 & 0.39 \\
\hline 5 & 6.77 & 1.40 & 1.40 & 0.90 & -1.35 & -2.33 & -2.50 & -2.04 & 1.90 & 2.65 & -0.75 & -0.02 & 0.77 \\
\hline 6 & 4.22 & -0.64 & 0.28 & 1.94 & 0.78 & -2.36 & -2.56 & -0.02 & 0.64 & 1.94 & -0.72 & 0.70 & 0.02 \\
\hline 7 & 4.36 & 0.72 & 1.05 & 1.22 & -0.95 & -2.04 & -2.76 & -1.96 & 1.77 & 2.96 & -0.32 & -0.21 & 0.53 \\
\hline 8 & 4.66 & 0.26 & 1.34 & 1.17 & -0.66 & -2.11 & -2.46 & -0.99 & 1.14 & 2.31 & -0.54 & -0.07 & 0.61 \\
\hline 9 & 3.13 & -0.05 & 0.62 & 0.37 & -0.47 & -0.47 & -2.13 & -2.13 & 0.27 & 4.00 & -0.2 & -0.10 & 0.32 \\
\hline 10 & 6.12 & 2.29 & 2.38 & -0.46 & -1.71 & -2.51 & -0.86 & -1.32 & 0.34 & 1.83 & -1.00 & -0.10 & 1.10 \\
\hline Av & 4.92 & 0.80 & 1.20 & 0.77 & -0.93 & -1.84 & -2.16 & -1.20 & 0.90 & 2.47 & -0.68 & 0.10 & 0.58 \\
\hline
\end{tabular}

$\mathrm{ID}=$ Participant identific ation number; $\mathrm{Av}=$ mean

Forest management alternatives: 1 . forest nature reserves; 2 . close-to-nature fores ts; 3 . combined objective forestry; 4. intensive even-aged forestry; 5 . wood biomass production.

Phases of development: $\mathrm{E}=$ establishment; $\mathrm{Y}=$ young; $\mathrm{M}=$ medium; $\mathrm{A}=$ adult

Tree species types: Con $=$ conifer; $\mathrm{B} / \mathrm{L}=$ broadleaved; $\mathrm{Mix}=$ mixed stands of conifer and broadleaved 